https://doi.org/10.37208/tgn27130

\section{New records of coral fungi: upright coral Ramaria stricta and greening coral Ramaria abietina from central Scotland}

\section{O’Reilly}

Scottish Environment Protection Agency, Angus Smith Building, 6 Parklands Avenue, Eurocentral, Holytown, North Lanarkshire ML1 4WQ

E-mail: myles.oreilly@sepa.org.uk

Coral fungi of the genus Ramaria form clumps of beautiful branching growths with a superficial resemblance to marine corals. There are around a dozen species in the British Isles, most of which are uncommon and seldom recorded (Buczacki et al., 2012).

During a visit to the King's Buildings Campus, University of Edinburgh, on 24th November 2011 numerous clumps of coral fungi, each around $10 \mathrm{~cm}$ in diameter and height, were observed spread over just a few square metres of a woodchip mulched border bed, adjacent to the West Mains Road entrance (NT26537078). A specimen was collected and sent to Professor Roy Watling who confirmed the identity as the upright coral (Ramaria stricta). This site was revisited three years later on 21st October 2014, when around 25 similar clumps of $R$. stricta were observed and photographed in the same border bed (Fig. 1).

On the 23rd September 2017, during a Clyde and Argyll Fungus Group (CAFG) foray in Victoria Park, Glasgow, an array of $R$. stricta growths was discovered, also in woodchip mulched border shrubbery, close to the children's play area (NS54056728). Again numerous clumps of fungi were observed among the bushes, but some of these had amalgamated into a spectacular wavy stand around $1 \mathrm{~m}$ long, $20 \mathrm{~cm}$ wide, and $15 \mathrm{~cm}$ in height (Fig. 2). This site was revisited in 2018, but late in the season on 28th December, when about 20 clumps of remnants of $R$. stricta were found in various states of decay. In 2018 the coral fungi clumps were about $10 \mathrm{~cm}$ in diameter with only one double clump about $20 \mathrm{~cm}$ in length.

On 26th October 2016 a group of seven clumps of greening coral ( $R$. abietina) were found growing among leaf litter under a Sawara cypress (Chamaecyparis pisifera) in the author's garden in Giffnock, Glasgow (NS55835902). R. abietina forms clumps around 3 - 5 $\mathrm{cm}$ in width and height. It has a distinct olive-green colouration but, despite this, is quite difficult to spot among leaf debris (Fig. 3).

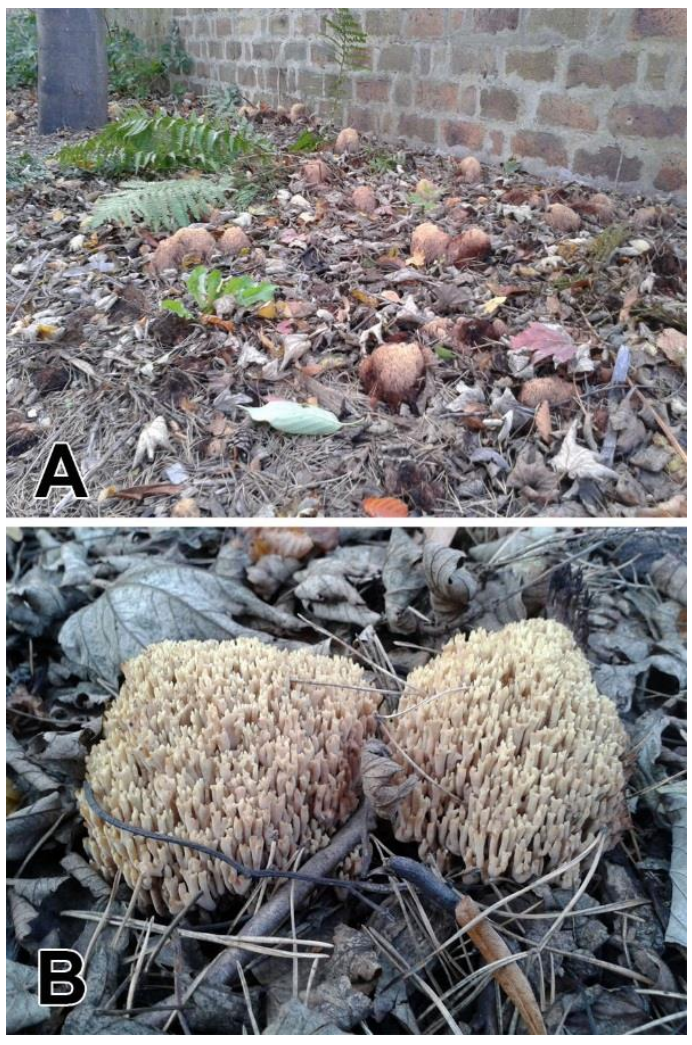

Fig. 1. Clumps of upright coral fungus (Ramaria stricta), King's Buildings Campus, University of Edinburgh, October 2014. (Photos: M. O'Reilly)
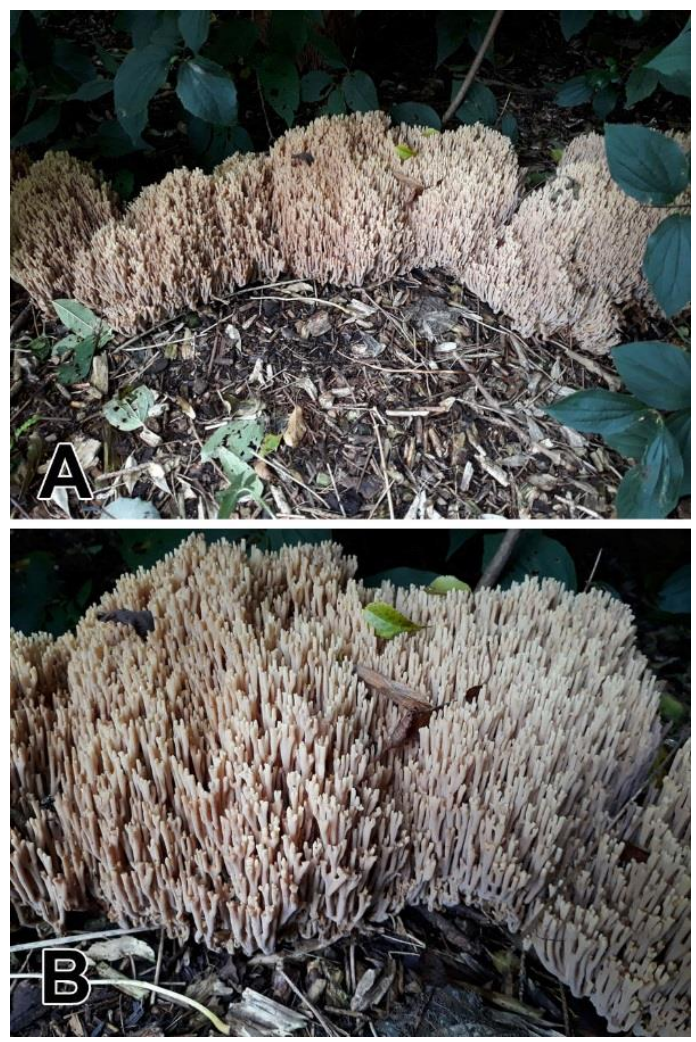

Fig. 2. Upright coral fungus (Ramaria stricta), Victoria Park, Glasgow, September 2017. (A) Large growth around $1 \mathrm{~m}$ long. (B) Close-up of growth around $10-15 \mathrm{~cm}$ high. (Photos: M. O'Reilly) 

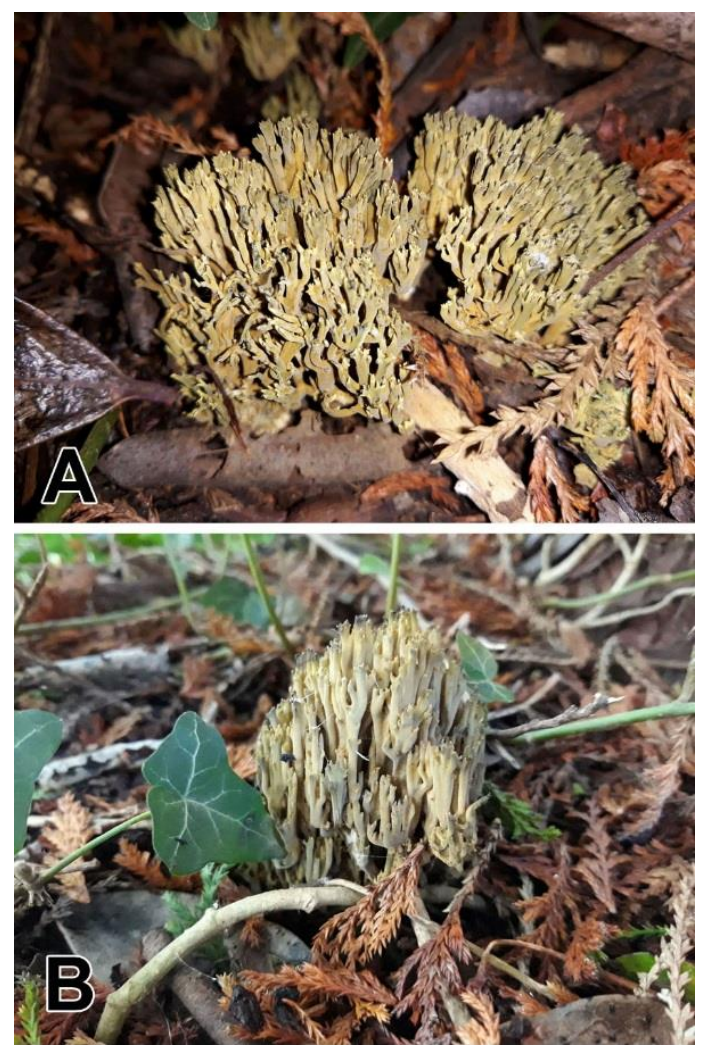

Fig. 3. Clumps of greening coral fungus (Ramaria abietina), around $5 \mathrm{~cm}$ high, on cypress leaf litter, Giffnock, Glasgow, October 2017. (Photos: M. O'Reilly)

Around ten clumps of $R$. abietina reappeared at the same location on 27th October 2017, and a single clump again on 17th November 2018. $R$. abietina material was also sent to Professor Roy Watling for confirmation.

The distributions of $R$. stricta and $R$. abietina in Scotland are quite similar, with most records in the north-east Highlands and just a couple each in southern Scotland (National Biodiversity Network, 2019). They are relatively uncommon with 14 and 32 Scottish records respectively shown on the National Biodiversity Network Atlas. However, the atlas shows relevant records only up to 2003/2004. The Fungal Records Database for Britain and Ireland (2019) holds more recent records, to October 2014 for $R$. stricta and October 2015 for $R$. abietina. For $R$. stricta the records from central Scotland include two from Glasgow (Blythswood Square, 2004; and Bell Street, Calton, 2011) and one from Chatelherault Country Park, Hamilton in 2010. For $R$. abietina the central Scotland records include Chatelherault (2004, 2005, and 2008), Edinburgh (Bawsinch, 2006), Lanark (2011), Kilsyth (Colzium Estate, 2011) and Glasgow (Bell Street, Calton, 2011). The site at Bell Street in Calton, Glasgow is of interest holding both species simultaneously. $R$. stricta occurs naturally on decaying wood but is known to thrive on mulched wood-chippings and might be expected to become more common with the increasing use of such mulches in suburban areas. R. abietina is associated with coniferous needle litter and many records originate from conifer plantations. However, exotic conifers in suburban areas offer an equally acceptable habitat. Hence both of these unusual species should be looked out for in suburban parks and gardens where they may be currently overlooked.

Thanks are due to Professor Roy Watling (Edinburgh Royal Botanic Gardens) for confirming the identifications.

\section{REFERENCES}

Buczacki, S., Shields, C. \& Ovenden, D. (2012). Collins Fungi Guide. The Most Complete Guide to the Mushrooms \& Toadstools of Britain \& Ireland. Harper Collins Publishers, London.

Fungal Records Database of Britain and Ireland. (2019). www.frdbi.info/ (Online accessed 11.3.2019).

National Biodiversity Network (2019). National Biodiversity Network Atlas. https://species.nbnatlas.org/ (Online: accessed 3.2.2019) 